Editorial

International Journal of Biological Sciences

ISSN 1449-2288 www.biolsci.org 2007 3(7):417-419

CIvyspring International Publisher. All rights reserved

\title{
In Celebration of Dr. Mario R. Capecchi's Nobel Prize
}

\section{Chuxia Deng}

Editor-in-Chief of International Journal of Biological Sciences, NIDDK, National Institutes of Health, 10/9N105, 10 Center Drive, Bethesda, MD 20892, USA

Correspondence to: Chu-Xia Deng, Ph.D., Tel: (301) 402-7225; Fax: (301) 480-1135; Email: chuxiad@bdg10.niddk.nih.gov

Received: 2007.10.16; Accepted: 2007.10.17; Published: 2007.10.17

This year, the Nobel Prize in Physiology or Medicine goes to Drs. Mario R. Capecchi, Martin J. Evans and Oliver Smithies for their discoveries of principles for introducing specific gene modifications in mice by the use of embryonic stem (ES) cells. This technology, commonly referred to as gene targeting or knockout, is based on homologous recombination between DNA sequences residing in the chromosome and newly introduced DNA to mutate any genes of interesting in mouse genome [1].

Twenty years ago, Capecchi and Smithies reported the targeted disruption of the hypoxanthine-guanine phosphoribosyl transferase gene (Hprt) [2], and the targeted correction of a defective Hprt allele [3], respectively, using the ES technology developed by Evans [4]. Since then, gene targeting has proven to be a powerful means of precisely manipulating the mammalian genome, generating at least ten thousand mutant mouse stains. Studies of these mutant mice have yielded enormously useful information in virtually all fields of biological and biomedical sciences. Indeed, gene targeting in ES cells can theoretically be used to generate mutant mice for all genes in the near future.

Dr. Capecchi's ground-breaking work for gene targeting started well before 1987. In 1980, he demonstrated high efficiency of transformation by directly microinjecting plasmid DNA into cultured mammalian cells [5]. This work led to his important conclusion that mammalian somatic cells possess an efficient enzymatic machinery for mediating homologous recombination [6]. He reasoned that if this machinery could be efficient for homologous recombination between a newly introduced DNA molecule and the endogenous DNA sequence, any host gene could be mutated. To demonstrate this principle, he generated recipient cell lines carrying an artificial target, a defective neomycin resistance gene that was stably integrated into host chromosome, and was able to repair it by injecting the same gene carrying a different mutation into the nucleus of these cells [7]. The correction occurred in one cell per 1,000 injected cells, a relatively high frequency, which makes it possible to use homologous recombination to manipulate endogenous genes of the mammalian genome.

These studies led to his successful targeted disruption of the first endogenous gene, Hprt, in ES cells in 1987, as mentioned earlier [2]. In this important study, Drs. Thomas and Capecchi used both replacement and insertional vectors to introduce a neomycin resistance (neor) gene into exon 8 of the Hprt gene, showing that clones of transfected cells had lost HPRT function (becoming 6-TG resistant), and had gained $\mathrm{Neo}^{\mathrm{r}}$ activity. Therefore, the HPRT-deficient cells could be easily selected. In their paper, they concluded "It is hoped that this combination of using ES cells as the recipient cell line and site-specific mutagenesis achieved by gene targeting will provide the means for generating mice of any desired genotype" [2].

However, a technical obstacle has to be overcome to achieve this goal because unlike Hprt, none of the other genes has a selective advantage after disruption. To solve this, Drs. Mansour, Thomas and Capecchi developed a strategy, called "Positive-Negative Selection" for enriching ES cells containing a targeted disruption of any transfected gene [8]. Dr. Capecchi also provided critical improvements in targeting efficiencies and accuracy [1, 9-11]. Many human disease-associated mutations are point mutations involving single nucleotide change. Introduction of these types of mutation is a challenge in the early stages of gene targeting. Using Hprt and the cystic fibrosis transmembrane conductance regulator (Cftr) genes, Capecchi and colleagues demonstrated that specific alterations (i.e. the F508 of CFTR, small deletion or insertion, and later, a loxP site for conditional mutations) that are placed several $\mathrm{kb}$ away from the selection marker could be co-transferred into ES cells through a double crossover event [12]. Importantly, they demonstrated that targeting efficiencies were strongly dependent upon the extent of homology between exogenous and endogenous DNA sequences, and that targeting vectors prepared from isogenic DNA targeted four to five times more efficiently than did the corresponding vectors prepared from nonisogenic DNA [10]. Thus, since 
then, the proper length of an isogenic targeting construct combined with the powerful "Positive-Negative Selection" has been the most widely used technique for mutating hundreds and thousands of genes in the mouse.

As a former PhD student of Dr. Capecchi (from 1986 to 1992), I have a special reason to celebrate this long awaited, and most prestigious and honorable prize to him. I can hardly describe how excited I was when I first heard that Dr. Capecchi has won the 2007 Nobel Prize in Physiology or Medicine. I felt that I was very lucky and honored to be one of his former students!

Dr. Capecchi's success sets an example for new generations of scientists. He had a difficult childhood, wandering in war-time Italy. He could not read and write until 9 years of age, when his mother found him on street and his uncle brought him to the USA. When talking about his childhood, this resourcefulness, as he put it, served as "the drive to keep yourself, maintain yourself, and survive". "And I think now I'm also very grateful, in a sense it's fantastic. I mean most children didn't make it, I think I was extremely lucky" [13]. Indeed, Mario was extremely lucky after he arrived in USA, finishing his schooling and having a marvelous opportunity to be trained by James Watson and Walter Gilbert, two Nobel laureates, for his graduate work!

His early experiences made him more independent of outside support and able to use his own resources wisely to get through life. Indeed, when his initial grant proposal to test the feasibility of gene targeting in mammalian cells was rejected, Mario managed to continue the work using limited funds saved from other projects. Even after he had adequate funds, receiving millions after the publication of the Cell paper in 1987, his budgets were carefully managed. He knows how important it is to get every dollar working for the research projects. I remember in 1991 when we moved our laboratory from the Biology Building to a new building sponsored by Howard Hughes Medical Institute, several students and I discarded some old or partially damaged equipment, but Mario requested us to pick them up and move to the new laboratory. On the other hand, when Harvard Medical School tried to recruit him in 1989 with better conditions, he declined it. He told us that the condition of University of Utah was good enough for all the experiments he would like to perform.

Now, gene targeting has reached a very fruitful stage, with approximately a half of all genes in mouse genome (about 22,400 genes) mutated. Targeting strategies have been expanded to all different kinds of modifications, including point mutations, isoform deletions, mutant allele correction, large pieces of chromosomal DNA insertion and deletion, tissue specific disruption combined with spatial and temporal regulation and so on. The ability to generate mouse models with predictable phenotypes will continue to have a major impact on studies of all phases of development, immunology, neurobiology, oncology, physiology, metabolism, and human diseases. In addition to the improvement of the human health, gene targeting is also, in theory, applicable to species from which totipotent ES cells can be established, and therefore has a potential to the improvement of domestic animals and plants.

The future of gene targeting is bright, although there is a long way to achieve all of these goals. Mario used to be a long distance runner, running about 8 miles each day. Apparently, he could not keep up this physical activity forever, but he remains a front-runner in science. Several months ago, we had a proposal to have a symposium to celebrate his 70 years anniversary in October of 2007. He told us that it was not the right time to celebrate because it might give people impression that he would retire soon. He would like to continue to work until 79 years of age. Now, with his Nobel Prize, it is the right time and we have a great reason to celebrate. Mario, congratulations on your achievement and great award!

\section{Acknowledgements}

This work was supported in part by the intramural Research Program of National Institute of Diabetes, Digestive and Kidney Diseases, National Institutes of Health, USA.

\section{References}

1. Capecchi MR. Altering the genome by homologous recombination. [Review]. Science 1989; 244: 1288-92.

2. Thomas KR, and Capecchi MR. Site-directed mutagenesis by gene targeting in mouse embryo-derived stem cells. Cell 1987; 51: 503-12.

3. Doetschman T, Gregg RG, Maeda N, Hooper ML, Melton DW, Thompson S, and Smithies O. Targetted correction of a mutant HPRT gene in mouse embryonic stem cells. Nature 1987; 330: 576-8.

4. Evans MJ, and Kaufman MH. Establishment in culture of pluripotential cells from mouse embryos. Nature 1981; 292: 154-6.

5. Capecchi MR. High efficiency transformation by direct microinjection of DNA into cultured mammalian cells. Cell 1980; 22: 479-88.

6. Folger KR, Wong EA, Wahl G, and Capecchi MR. Patterns of integration of DNA microinjected into cultured mammalian cells: evidence for homologous recombination between injected plasmid DNA molecules. Mol Cell Biol 1982; 2: 1372-87.

7. Thomas KR, Folger KR, and Capecchi MR. High frequency targeting of genes to specific sites in the mammalian genome. Cell 1986; 44: 419-28.

8. Mansour SL, Thomas KR, and Capecchi MR. Disruption of the proto-oncogene int- 2 in mouse embryo-derived stem cells: a general strategy for targeting mutations to non-selectable genes. Nature 1988; 336: 348-52.

9. Mansour SL, Thomas KR, Deng CX, and Capecchi MR. Introduction of a lac $Z$ reporter gene into the mouse int-2 locus by homologous recombination. Proc Natl Acad Sci U S A 1990; 87: 7688-92.

10. Deng C, and Capecchi MR. Reexamination of gene targeting frequency as a function of the extent of homology between the targeting vector and the target locus. Mol Cell Biol 1992; 12: 3365-71.

11. Thomas KR, Deng C, and Capecchi MR. High-fidelity gene targeting in embryonic stem cells by using sequence replacement vectors. Molecular \& Cellular Biology 1992; 12: 2919-23. 
Int. J. Biol. Sci. 2007, 3

12. Deng C, Thomas KR, and Capecchi MR. Location of crossovers during gene targeting with insertion and replacement vectors. Mol Cell Biol 1993; 13: 2134-40.

13. [Internet] Smith A. Telephone interview with Mario R. Capecchi. http://nobelprize.org/nobel_prizes/medicine/laureates/2007/ capecchi-interview.html. 